\title{
Autism spectrum disorder: prevalence and cause may be bound together ${ }^{\dagger}$
}

\author{
Emily Simonoff
}

\begin{abstract}
Summary
Autism has been in the forefront of science and public concern because of reported increases in its prevalence. Changing diagnostic practice and improved identification explain some of this rise, but there may also be a true increase. Aetiological research needs to
\end{abstract}

include environmental factors to understand the causes of autism.

\section{Declaration of interest}

None.
Emily Simonoff is Professor of Child and Adolescent Psychiatry, Department of Child and Adolescent Psychiatry, King's College London, Institute of Psychiatry, and National Institute for Health Research Biomedical Research Centre for Mental Health, London.

In this issue, Bejerot and colleagues ${ }^{1}$ challenge the 'extreme male brain' hypothesis of autism causation proposed by Baron-Cohen ${ }^{2}$ in which he argues that the environmental effect of fetal testosterone on brain development influences variation in personality characteristics related to autism. Bejerot et al used a case-control design to examine physical measures purportedly related to androgen levels. Their findings are not straightforward but are most consistent with increased androgyny in adults with autism, as they found evidence favouring increased androgen influence in females with autism compared with decreased androgens in males with autism. The role of environmental risk factors in autism has been subsumed in recent years to that attributed to genetic factors. Since twin studies revealed large differences in monozygotic and dizygotic concordance rates and dashed the 'refrigerator mother' hypothesis, science has focused on genetic causation of autism. The same studies that highlighted the importance of genetic factors were also the ones demonstrating that autism should be conceptualised as the extreme end of disorders and traits affecting social reciprocity and communication. By showing that monozygotic twins were concordant not for the diagnosis of autism but rather for severe impairments in social reciprocity and communication, ${ }^{3}$ the seed was planted for the dimensional view of liability to autism that has been substantiated in more recent population-based twin studies. ${ }^{4}$ Genetic studies underpin the concepts of the 'autism spectrum', comprising childhood autism, Asperger syndrome, atypical autism and other pervasive developmental disorders.

\section{Diagnostic criteria and increased prevalence rates}

At the same time, there has been a steady rise in reported prevalence rates, culminating in the most recent estimate of $2.6 \%$ from Korea. ${ }^{5}$ These increases have provoked both scientific scrutiny and public anxiety. There is general consensus that broadening diagnostic boundaries, improved identification and public awareness, diagnostic substitution and access to services all play a role. There is, however, no evidence that people without significant impairment are currently being diagnosed. For

'See pp. 109-115 and 116-123, this issue. example, a UK study showed that $42 \%$ of 11 - to 12 -year-olds meeting consensus criteria for autism spectrum disorder (ASD) had not been so identified by services - but virtually all had at least one other diagnosis. ${ }^{6}$ However, the DSM-5 Working Group has been concerned about the current diagnostic criteria and is proposing significant changes. The DSM-IV criteria allow an ASD diagnosis if there are sufficient symptoms of impairments in social reciprocity and communication, and do not require the presence of repetitive and stereotyped behaviours and interests. The proposed modifications require the latter symptoms also to be present in the new diagnostic category of ASD. It is suggested that the newly proposed and as yet loosely specified diagnosis of social communication disorder could apply to individuals without repetitive and stereotyped behaviours and interests, who previously would have received a diagnosis in the autism spectrum cluster. The impact of the proposed changes on diagnostic rates is uncertain but hotly debated. Two published studies suggest it will exclude individuals captured by the current criteria, ${ }^{7,8}$ creating concern among those with a current diagnosis, their carers and clinicians.

\section{Environmental and genetic risk factors}

The important unanswered question is whether ASD has truly increased or whether the secular trends in diagnostic practice and identification fully account for the rise. Without a diagnostic biomarker, the question cannot be conclusively answered. If there were a true increase, what might the mechanism be? Although substantial or rapid increases in the rate of ASD are inconsistent with polygenic inheritance, other genetic mechanisms could explain this. De novo mutations provide one potential mechanism for a true increase. New molecular techniques have allowed the genome-wide identification of small, submicroscopic genetic deletions and duplications (often called copy number variants, $\mathrm{CNVs}$ ), and case-control studies in several psychiatric disorders, including autism, schizophrenia and intellectual disability, have pointed to a causal role for these factors. The extent of their role in ASD remains uncertain and if they turn out to be an important cause, the question to be addressed is why CNVs should be increasing.

Most twin studies estimate heritability at $90 \%$ and appear to leave little scope for an influential role of environmental risk factors. However, this is a misconception, both because even small amounts of independent environmental variance can have substantial phenotypic effects and also because heritability estimates contain any effect of gene-environment interplay - both 
gene-environment correlation and gene-environment interaction. Thus, environmental factors provide a potential explanation for increasing rates of autism. Postulating a role for environmental factors has always been popular among autism researchers and parents/carers, but not necessarily grounded in good science and sometimes creating public health hazards. The link to the measles, mumps and rubella vaccination, now robustly refuted by wideranging research, had a significant impact on immunisation uptake and herd immunity. However, bad science should not lead to wholesale rejection of the role of environmental factors in autism. The high rate of 'quasi-autism' in UK Romanian adoptees suggests that severe deprivation can have a profound and lasting impact on the development of social communication. ${ }^{9}$

In another article in this issue, Magnusson et al ${ }^{10}$ carefully examined the relationship between rates of ASD and parental migration in Sweden. They reported an association between low-functioning autism and migration from countries of lower economic development, with highest rates occurring when migration occurred during pregnancy. The results are tantalising because the same risk group had lower rates of ASD with normal IQ and the confounders tested were limited (time since mother's migration, maternal age, family income and small for gestational age). The study requires replication in other populations but it nevertheless points to the potential value of carefully conducted research that is able to identify putative environmental factors and then to explore their mechanisms. Birth cohort studies, commencing prenatally or in very early infancy and designed to measure possible environmental and genetic risk factors, should provide important contributions, but large sample sizes are required. The Norwegian $\mathrm{ABC}$ study $^{11}$ is one such example, as is the planned UK Birth Cohort Study, due to commence in 2013.

\section{Future research in autism}

The lessons from other psychiatric disorders show that we should expect aetiological heterogeneity and gene-environment interplay when identifying causal factors. A failure to identify and measure environmental risk factors leads to misspecification of the disease mechanisms, as illustrated for depression. Although the geneenvironment interaction between the serotonin transporter and life events is now conclusively demonstrated, genome-wide association studies of depression looking for main genetic effects do not identify the serotonin transporter as a genetic risk factor. For autism, although individual genes of small effect are now being identified, there is a risk that the mechanisms of disorder will only be understood when they are studied in the context of environmental factors. The future of causal research in autism needs to consider both genetic and environmental factors and to begin to identify models of joint action. Whether or not prevalence rates are truly increasing, this strategy offers the most promise for prevention and intervention.

Emily Simonoff, MD, FRCPsych, Department of Child and Adolescent Psychiatry, Institute of Psychiatry, De Crespigny Park, London SE5 8AF, UK. Email: emily.simonoff@kcl.ac.uk

First received 11 Oct 2011, final revision 22 Jun 2012, accepted 26 Jun 2012

\section{References}

1 Bejerot S, Eriksson JM, Bonde S, Carlström K, Humble MB, Eriksson E. The extreme male brain revisited: gender coherence in adults with autism spectrum disorder. Br J Psychiatry 2012; 201: 116-23.

2 Baron-Cohen S. Empathizing, systemizing, and the extreme male brain theory of autism. Prog Brain Res 2010; 186: 167-75.

3 Bailey AJ, Le Couteur A, Gottesman I, Bolton P, Simonoff E, Yazda E, et al. Autism as a strongly genetic disorder: Evidence from a British twin study. Psychol Med 1995; 25: 63-77.

4 Robinson EB, Koenen KC, McCormick MC, Munir K, Hallett V, Happe F, et al. Evidence that autistic traits show the same etiology in the general population and at the quantitative extremes (5\%, 2.5\%, and 1\%). Arch Gen Psychiatry 2011; 68: 1113-21.

5 Kim YS, Leventhal BL, Koh YJ, Fombonne E, Laska E, Lim EC, et al. Prevalence of autism spectrum disorders in a total population sample. Am J Psychiatry 2011; 168: 904-12.

6 Baird G, Simonoff E, Pickles A, Chandler S, Loucas T, Meldrum D, et al. Prevalence of disorders of the autism spectrum in a population cohort of children in South East Thames - The Special Needs and Autism Project. Lancet 2006; 368: 210-5.

7 Mandy WP, Charman T, Gilmour J, Skuse DH. Toward specifying pervasive developmental disorder - not otherwise specified. Autism Res 2011; 4 $121-31$.

8 Mattila ML, Kielinen M, Linna SL, Jussila K, Ebeling $H$, Bloigu R, et al. Autism spectrum disorders according to DSM-IV-TR and comparison with DSM-5 draft criteria: an epidemiological study. J Am Acad Child Adolesc Psychiatry 2011; 50: 583-92.e11.

9 Rutter M, Andersen-Wood L, Beckett C, Bredenkamp D, Castle J, Groothues C, et al. Quasi-autistic patterns following severe early global privation. English and Romanian Adoptees (ERA) Study Team. J Child Psychol Psychiatry 1999; 40: 537-49.

10 Magnusson C, Rai D, Goodman A, Lundberg M, Idring S, Svensson A, et al. Migration and autism spectrum disorder: population-based study. $\mathrm{Br} \mathrm{J}$ Psychiatry 2012; 201: 109-15.

11 Stoltenberg C, Schjølberg S, Bresnahan M, Hornig M, Hirtz D, Dahl C, et al. The Autism Birth Cohort ( $\mathrm{ABC}$ ): a paradigm for gene-environment-timing research. Mol Psychiatry 2010; 15: 676-80. 